\title{
Medical Inertia in the Optimization of Heart Failure Treatment after Discharge and its Relationship to Outcome
}

Berthelot $E^{1}$, Eicher $\mathrm{JC}^{2}$, Salvat $\mathbf{M}^{3}$, Seronde $\mathrm{MF}^{4}$, de Groote ${ }^{5}$, Jondeau $\mathbf{G}^{6}$, Galinier $\mathbf{M}^{7}$, Roul $\mathbf{G}^{7}$, Donal E ${ }^{8}$, Damy ${ }^{9}$, Jourdain $\mathbf{P}^{10}$, Bauer $\mathrm{F}^{11}$, Isnard $\mathbf{R}^{12}$, Trochu $\mathrm{JN}^{13}$, Damien Logeart ${ }^{14^{*}}$ and On behalf of Gicc-HF.

${ }^{1} A P-H P$, Service de Cardiologie, Hopital Bicetre, Le Kremlin-Bicetre, France

${ }^{2}$ Centre Hospitalier Universitaire, Dijon, France

${ }^{3}$ Centre Hospitalier Universitaire, Grenoble, France

${ }^{4}$ Centre Hospitalier Universitaire Minoz, Besancon, France

${ }^{5}$ Centre Hospitalier Regional Universitaire de Lille, France

${ }^{6}$ AP-HP, Groupe Hospitalier Bichat Claude Bernard, France

${ }^{7}$ Centre Hospitalier Universitaire Rangueil, Toulouse, France

${ }^{8}$ Centre Hospitalier Universitaire Pontchaillou, Rennes, France

${ }^{9}$ AP-HP, Hopital Henri Mondor, Creteil, France

${ }^{10}$ Centre Hospitalier Rene Dubosc, Pontoise, France

${ }^{11}$ Hopital Charles Nicolle, Rouen, France

${ }^{12}$ AP-HP, Groupe Hospitalier Pitie Salpetriere, Paris, France

${ }^{13}$ Inserm UMR1087, Centre Hospitalier Universitaire Nantes, Université de Nantes, Nantes, France

${ }^{14}$ Inserm U942, AP-HP, Groupe Hospitalier Lariboisiere Saint Louis, Paris Diderot University, Paris, France

\begin{abstract}
Background: After discharge, patients with Acute Heart Failure (AHF) have a high risk of early re-admission and death. Many patients are discharged early before treatment has been optimized. By using a multicenter cohort of AHF patients, we analyzed changes in evidence-based HF medication between admission, discharge and early follow-up as well as their links to mortality.

Methods: Clinical data and medications were collected during hospitalization. Changes in medication during the 3 months following discharge as well as the rate of all-cause mortality at one year were analyzed.

Results: Among survivors at 3 months, 275 patients with LVEF $\leq 40 \%$ were included (age $72 \pm 14$ y). Between admission and discharge, usage of angiotensin converting enzyme inhibitor (ACE-I) or angiotensin receptor blocker (ARB) and beta blocker (BB) increased by 19 to $20 \%$ and MRA by $8 \%$. At discharge, ACE-I or ARB were prescribed in $80 \%$ of cases with the mean dose reaching $36 \pm 31 \%$ of target dose, BB in $70 \%$ with the mean dose of $27 \pm 51 \%$ of the target dose, mineraloreceptor antagonists (MRA) were prescribed in $23 \%$ and diuretics in $88 \%$ cases. Three months after discharge, there were few changes in medications. Start in ACE-I or ARB, beta-blockers and MRA was performed in 3 to $7 \%$ while cessation was performed in 5 to $6 \%$ cases. Changes in doses were observed in about $25 \%$ cases. usage of BB and Ace ORARB $>/ \%$ of target dose at 3 months shows a tendency to deusage montality [ $H R=5,2999 ; 95 \%$ ic1,7369-16-1722; $p=0,0635]$.
\end{abstract}

Conclusion: Our data points out inertia in optimization of evidence-based HF medications after discharge and focus on potential explanations of such inertia. Medical ineatia have a potential impaction on outcomein heart failure.

Keywords: Heart failure; Medical treatment; Inertia; Outcome

Abbreviations: ACE-I: Angiotensin Converting Enzyme Inhibitor; AHF: Acute Heart Failure; ARB: Angiotensin Receptor Blocker; BB: Beta-Blocker; COPD: Chronic Obstructive Pulmonary Disease; LVEF: Left Ventricular Ejection Fraction; HF-REF: Heart Failure with Reduced LVEF; ICD: Implantable Cardiac Defibrillator; MRA: Mineralocorticoid Receptor Antagonist

\section{Introduction}

Heart failure (HF) is a major and increasing cause of morbidity and mortality [1-4]. The risk of cardiac events is particularly high just after discharge. Over the last decades, major advances have occurred in the medical treatment of patients with HF and reduced left ventricular ejection fraction (LVEF), including ACE-inhibitors (ACE-I), Angiotensin receptors blockers (ARB), beta-blockers (BB), mineralocorticoid receptor antagonists (MRA), ivabradine and recently LCZ696. This has led to the production of robust guidelines to support physicians in the clinical decision-making of HF patients with reduced LVEF $[5,6]$. Some surveys have noted that many of these patients do not receive evidence-based treatment at all, or do receive treatment but without optimal dosages, despite physicians being increasingly encouraged to apply the guidelines to their practice [7-10]. The reasons are numerous, including the patient's condition (age, comorbidities, adherence) as well as the physician's choices (ignorance of the guidelines, misgivings about new treatment, focus on patient symptoms rather than reduction of mortality), and access to health care [9-14]. However, data on changes in treatment over follow-up are scarce, particularly during the early follow-up of patients after an acute HF event. In order to bridge this gap of information by using a representative sample of AHF patients with reduced LVEF from a nationwide survey, we analyzed the usage of evidence-based HF medications on admission and discharge

*Corresponding author: Damien Logeart, Hopital Lariboisiere 2 Rue Ambroise Pare, 75010 Paris, France, Tel +33149956565; Fax 33149958439; E-mail damien.logeart@aphp.fr

Received December 07, 2017; Accepted February 15, 2018; Published February 22, 2018

Citation: Berthelot E, Eicher JC, Salvat M, Seronde MF, de Groote P, et al. (2018) Medical Inertia in the Optimization of Heart Failure Treatment after Discharge and its Relationship to Outcome. Health Care Current Reviews 6: 221. doi: 10.4172/2375-4273.1000221

Copyright: (c) 2018 Berthelot E, et al. This is an open-access article distributed under the terms of the Creative Commons Attribution License, which permits unrestricted use, distribution, and reproduction in any medium, provided the original author and source are credited. 
as well as the changes at 3 months and subsequent links to mortality after one year.

\section{Methods}

We analyzed data from the nationwide survey known as OFICA (NCT01080937). Methods and the main results of this survey have been described in a previous paper [15]. Briefly, this survey included all hospitalized patients with a confirmed diagnosis of AHF in 170 hospitals on one single day, resulting in 1658 patients of whom 1524 were discharged alive. Clinical characteristics including LVEF as well as biological variables (creatininemia, hemoglobin, natriuretic peptides) and treatments were recorded during hospitalization. Changes in treatment between admission and discharge as well as during the 3 \pm 1 months following discharge was studied. Changes after discharge were recorded by participating hospitals on a voluntary basis, and by calling referring physicians as well as patients. For the present study, only patients with LVEF $\leq 40 \%$ were analyzed. Figures for one-year total mortality after discharge were obtained from the national registry of death (Inserm CepiDC). All patients gave informed consent at the time of inclusion.

\section{Statistical analysis}

Continuous variables were expressed as mean \pm SD or median (1st and 3rd quartiles) and categorical variables were expressed as frequency and/or percentages. Differences between groups were assessed by 1-way ANOVA with a post hoc Bonferroni's test for multiple comparisons. Categorical variables were compared by using the chi-squared test. Variables associated with prescription of ACE-I/ARB and beta-blockers were studied using logistic regression with all baseline characteristics. Then a stepwise multivariate logistic regression (rearward exclusion iterations) using significant predictors from the univariate analysis $(\mathrm{p}<0.20)$ was performed. A stepwise cox analysis was performed with the parameters influencing survival. Kaplan Meier survival curves were drawn depending on the prescription of the HF treatment with target dose $\geq 50 \%$. Hazard ratios (HRs) with a $95 \% \mathrm{CI}$ are given as association measures. All tests were two-sided using a significance level of 0.05 . Analyses were performed using MedCalc software.

\section{Results}

Among the 1522 survivors at discharge in the OFICA study, a specific follow-up of prescribed medications after discharge was performed by 59 of the 170 participating hospitals resulting in a cohort of 592 patients. Among these 592 patients, only 519 patients of whom 275 had LVEF $\leq$ $40 \%$, had at least one consultation during the 3 months after discharge and the data was analyzed. The main clinical characteristics as well as discharge clinical and biological variables and treatments are reported in Table 1 and compared to surviving patients at discharge with LVEF $\leq 40 \%$ of the whole OFICA cohort $(n=733)$. There was no significant difference between the two groups among all studied variables (Table 1).

The usage of classes of cardiovascular agents on admission, at discharge and at 3 months is detailed in Table 2. The usage of ACE-I or ARB as well as beta-blockers or loop diuretics increased by 20 to $30 \%$ when the usage of MRA increased by only $8.4 \%$ from admission to discharge. Among beta-blockers on admission, there were only $39.2 \%$ beta-blockers that are recommended by guidelines. The rate of antithrombotic agents as well as amiodarone also increased during hospitalization. In contrast, there was no significant change between the time of discharge and 3 months after discharge in the mean rate of prescriptions or dosing of evidence based-HF drugs. The Figure 1 detailed further changes in prescription of loop diuretics, ACE-I or

\begin{tabular}{|c|c|c|}
\hline & $\begin{array}{c}\text { OFICA cohort } \\
\text { LVEF } \leq 40 \% \\
n=733\end{array}$ & $\begin{array}{c}\text { Study subgroup } \\
\text { LVEF } \leq \mathbf{4 0} \% \\
n=275\end{array}$ \\
\hline Age (years) & $76.1(63.3-83.1)$ & $75.1(64.5-82.2)$ \\
\hline Gender (male) & $67 \%$ & $66 \%$ \\
\hline Previous hospitalization for AHF & $46 \%$ & $42 \%$ \\
\hline Ischemic heart disease & $45 \%$ & $44 \%$ \\
\hline COPD & $19 \%$ & $22 \%$ \\
\hline Hypertension & $53 \%$ & $53 \%$ \\
\hline Diabetes & $34 \%$ & $26 \%$ \\
\hline BMI $\left(\mathrm{kg} / \mathrm{m}^{2}\right)$ & $26.2(23.0-30.2)$ & $25.8(22.5-30.9)$ \\
\hline LVEF & $30.0(22.0-35.5)$ & $31.5(25.0-40.0)$ \\
\hline Sinus rythm & $57 \%$ & $60 \%$ \\
\hline Systolic BP (mmHg) & $110(99-127)$ & $110(100-130)$ \\
\hline Heart rate $(\mathrm{bpm})$ & $74(65-84)$ & $70(64-80)$ \\
\hline Hemoglobin (g/dL) & $12.0(10.7-13.6)$ & $12.3(11.0-13.5)$ \\
\hline Creatininemia (mg/l) & $13.0(10.2-17.4)$ & $12.5(10.2-17.0)$ \\
\hline Kaliemia (mmole/L) & $4.3(3.9-4.6)$ & $4.3(4.0-4.6)$ \\
\hline Worsening renal function* & $47 \%$ & $47 \%$ \\
\hline Discharge DFG $<30 \mathrm{ml} / \mathrm{min} / 1.72 \mathrm{~m}^{2}$ & $19 \%$ & $19 \%$ \\
\hline $\mathrm{BNP}(\mathrm{pg} / \mathrm{ml})$ & $627(327-1471)$ & $481(271-1175)$ \\
\hline NT proBNP (pg/ml) & $3528(1346-8482)$ & $2517(1310-6482)$ \\
\hline Loop diuretics & $88.6 \%$ & $88 \%$ \\
\hline ACE-I or ARB & $77.7 \%$ & $79.6 \%$ \\
\hline Beta-blockers & $67.4 \%$ & $69.8 \%$ \\
\hline ACE (or ARB) and beta-blockers & $57.9 \%$ & $59.6 \%$ \\
\hline Mineraloreceptor antagonists & $26.6 \%$ & $23.3 \%$ \\
\hline
\end{tabular}

This table shows clinical and biological variables at discharge as well as treatment * worsening renal function was defined by increase in creatininemia $\geq 0.3 \mathrm{mg} / \mathrm{L}$ between admission and discharge.

Table 1: Baseline characteristics of patients with LVEF $<40 \%$ from the whole OFICA study and in the subgroup of 275 patients with analysis of treatment at 3 months.

\begin{tabular}{|l|c|c|c|}
\hline & Admission & At discharge & At 3 months \\
\hline ACE-I & $46.5 \%$ & $66.2 \%$ & $64.9 \%$ \\
\hline At $\geq 50 \%$ of target dose & $65 \%$ & $42 \%$ & $42 \%$ \\
\hline at $100 \%$ of target dose & $34 \%$ & $13 \%$ & $14 \%$ \\
\hline ARB & $16.3 \%$ & $13.8 \%$ & $12.4 \%$ \\
\hline At $\geq 50 \%$ of target dose & $48 \%$ & $9 \%$ & $8 \%$ \\
\hline at $100 \%$ of target dose & $14 \%$ & $5 \%$ & $4 \%$ \\
\hline ACE-I or ARB & $62.8 \%$ & $79.6 \%$ & $76.3 \%$ \\
\hline At $\geq 50 \%$ of target dose & $60 \%$ & $51 \%$ & $48 \%$ \\
\hline at $100 \%$ of target dose & $27 \%$ & $19 \%$ & $19 \%$ \\
\hline Beta-blocker & $39.2 \%$ & $69.8 \%$ & $69.0 \%$ \\
\hline At $\geq 50 \%$ of target dose & $41 \%$ & $20 \%$ & $31 \%$ \\
\hline at $100 \%$ of target dose & $14 \%$ & $16 \%$ & $10 \%$ \\
\hline ACE-I or ARB and Beta-blockers & $40.1 \%$ & $59.6 \%$ & $54.7 \%$ \\
\hline Loop diuretics & $68.7 \%$ & $88.4 \%$ & $89.1 \%$ \\
\hline dose (mg of furosemide/d) & $107 \pm 157$ & $93 \pm 140$ & $94 \pm 152$ \\
\hline Mineraloreceptor antagonists & $14.9 \%$ & $23.3 \%$ & $24.8 \%$ \\
\hline Digitalis & $10.3 \%$ & $9.1 \%$ & $8.7 \%$ \\
\hline Calcium blockers & $12.2 \%$ & $10.9 \%$ & $10.1 \%$ \\
\hline Amiodarone & $16.3 \%$ & $20.7 \%$ & $21.5 \%$ \\
\hline Statins & $39.0 \%$ & $47.9 \%$ & $47.9 \%$ \\
\hline Aspirin & $36.7 \%$ & $33.5 \%$ & $33.1 \%$ \\
\hline Anticoagulant & $29.3 \%$ & $41.8 \%$ & $43.2 \%$ \\
\hline Number of drugs & $\mathrm{NA}$ & $8(6-10)$ & $8(6-10)$ \\
\hline Table Comparson & & & \\
\hline
\end{tabular}

Table 2: Comparison of rates of prescription at hospital discharge and at 3 months.

$\mathrm{ARB}$ and beta-blockers. Indeed, there was no change in use or dosage of ACE-I or ARB and beta-blockers in most patients after discharge. For 
Citation: Berthelot E, Eicher JC, Salvat M, Seronde MF, de Groote P, et al. (2018) Medical Inertia in the Optimization of Heart Failure Treatment after Discharge and its Relationship to Outcome. Health Care Current Reviews 6: 221. doi: 10.4172/2375-4273.1000221

Page 3 of 6

ACE-i or ARB

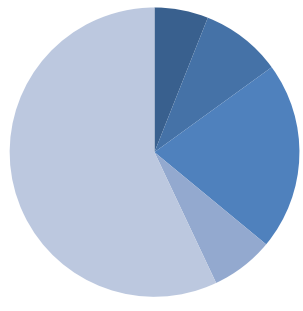

- Started

Stopped

- Increased

decreased

Unchanged

Betab lockers

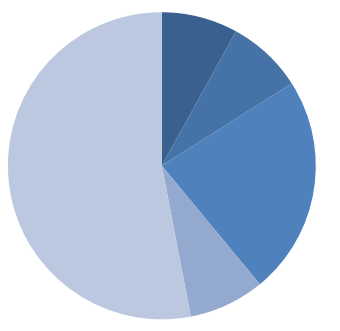

- Started

- Stopped

Increased

decreased

Unchanged

\section{Loop diuretics}

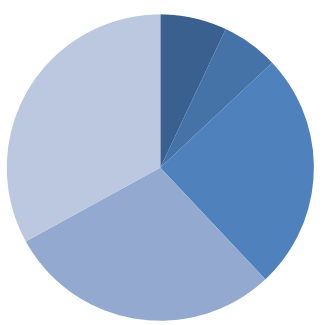

- Started

- Stopped

Increased

decreased

Unchanged

Figure 1: changes in rate of prescription as well as dose between discharge and 3 months.

ACE-I and beta-blockers respectively, increase in dosage after discharge was observed in 21 and $23 \%$ of patients. Decrease in dosage after discharge was observed in similar rates. There were few introductions or cessations of these treatments -6 to $-9 \%$ after discharge. Dosage of loop diuretics was increased in $25 \%$ and decreased in $26 \%$ of patients. In addition, mineraloreceptor antagonists were started in $7 \%$ and stopped in $5 \%$ of patients after discharge.

Table 3 shows variables that were associated with usage of ACE-I or ARB and beta-blockers at discharge as well as at 3 months. By using multivariate logistic regression, the usage of ACE-I or ARB at discharge $\geq 50 \%$ of target dose was significantly related to admission creatininemia (OR 0.95, 95\% CI 0.90-0.99, p<0.03), ACE-I or ARB treatment at admission (OR 0.5162, 95\% CI 0, 29-0.91, $\mathrm{p}<0.0242$ ) and ejection fraction (OR $0.96 \mathrm{CI} 95 \% 0.94-0.97, \mathrm{p}<0.03$ ). At 3 months after discharge, the usage of ACE-I or ARB $\geq 50 \%$ of target dose were significantly related to usage of ACE-I or ARB at discharge (OR 5.67, 95\% CI 3.06-10.51, $\mathrm{p}<0.0001$ ), age (OR 0.97, 95\% CI 0.95$0.99, \mathrm{p}<0.015)$ and the creatininemia at discharge (OR 1.0263, 95\% CI $0.99-1.06, p<0.18)$. The usage of beta-blockers $\geq 50 \%$ of target dose at discharge was significantly associated with usage of beta-blockers at admission (OR 1.00, 95\% CI 0.99-1.00, p<0.372), COPD (OR 1.68, 95\% CI $0.70-4.03, \mathrm{p}<0.24$ ), and ischemic heart disease (OR 1.5116,
95\% CI 0.67-3.40, $\mathrm{p}<0.37$ ); at 3 months after discharge, the usage of beta-blockers $\geq 50 \%$ of target dose was significantly related to usage of beta-blockers at discharge (OR 4.22, 95\% CI 2.20-8.08, $\mathrm{p}<0.0001)$ and COPD (OR 0.37, 95\% CI 0.18-0.75, $\mathrm{p}<0.0018$ ). Among the 275 patients who had survived at 3 months, all-cause mortality was $7.6 \%$ over the following 9 months. Mortality was related to age, HF duration, COPD, left ventricular ejection fraction, discharge heart rate, creatininemia and ACE-I or ARB and beta-blockers $\geq 50 \%$ of target dose. There was no significant difference in mortality related to the prescription or not of ACE-I or ARB and beta-blockers $\geq 50 \%$ of target dose at 3 months after discharge after adjustment on age, systolic blood pressure, creatininemia and LVEF (HR=5.2999; 95\% IC 1.7369 to 16.1722 ; $\mathrm{p}=0.0635$ ). But a clear tendency to deusage mortality. Figure 2 shows survival curves depending on the usage or not of HF treatments at 3 months ACE-I or ARB and beta-blockers $\geq 50 \%$ of target dose.

\section{Discussion}

This study has two main findings. Firstly, treatment at discharge was far from optimal Secondly, there was no increase in usage or dosage of evidence-based HF drugs during the first months after discharge, even though treatment at discharge was far from optimal. Our study shows that $40 \%$ of patients did not receive the combination ACE-I (or ARB) and beta-blockers and 75\% did not receive MRA 3 months after in our cohort. The use of MRA was particularly weak if we consider that the usual contra-indications. Insufficient adherence to guidelines has been pointed out for years, and numerous explanations have been given to explain the gap between real life and the guidelines [9-17] even if there has been improvement over time [18]. The ESC HF Long Term survey that was conducted from 2010 reported results close to ours for the usage of ACE-I/ARB and beta-blockers [9].

The post-discharge period has been called the 'vulnerable phase' of HF because of the very high risk of unplanned readmission or death [19]. Therefore optimization of treatment before and early after discharge is clearly mandatory. Our results show medical inertia in the management of HF patients early after discharge. Inertia has been widely discussed in the context of hypertension or diabetes leading to a campaign of sensitization among practitioners [20-22]. In the area of HF, inertia between discharge

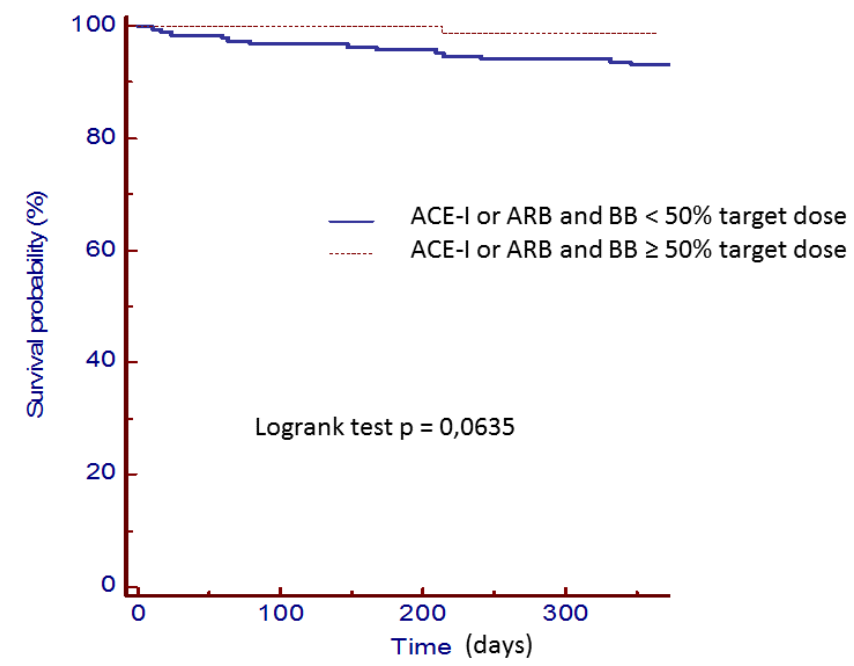

Figure 2: Kaplan meyer survival curves according to treatment with or without ACE-I or ARB and beta-blockers $\geq 50 \%$ of the target dose at 3 months. 
Citation: Berthelot E, Eicher JC, Salvat M, Seronde MF, de Groote P, et al. (2018) Medical Inertia in the Optimization of Heart Failure Treatment after Discharge and its Relationship to Outcome. Health Care Current Reviews 6: 221. doi: 10.4172/2375-4273.1000221

Page 4 of 6

\begin{tabular}{|c|c|c|c|c|c|c|}
\hline $\begin{array}{l}\text { ACE-I or ARB } \geq 50 \% \text { of } \\
\text { target dose discharge }\end{array}$ & OR & $\mathrm{Cl}$ & $\mathrm{p}$ & OR & $\mathrm{Cl}$ & $\mathrm{p}$ \\
\hline Age & 0,9871 & 0,9701 to 1,0043 & 0,1447 & & & \\
\hline Gender & 0,8189 & 0,4869 to 1,3774 & 0,4514 & & & \\
\hline Discharge creatininemia & 0,9564 & 0,9144 to 1,0002 & 0,0510 & 0,9372 & 0,8955 to 0,9806 & 0,0050 \\
\hline Hypertension & 0,7630 & 0,4676 to 1,2449 & 0,2788 & & & \\
\hline Diabetes & 1,5305 & 0,8772 to 2,6706 & 0,1340 & & & \\
\hline Ischemic heart disease & 1,5601 & 0,9550 to 2,5485 & 0,0757 & & & \\
\hline Treatment on admission & 0,5526 & 0,3201 to 0,9540 & 0,0333 & 0,5162 & 0,2905 to 0,9173 & 0,0242 \\
\hline Admission systolic blood pressure & 1,0037 & 0,9910 to 1,0165 & 0,5698 & & & \\
\hline Ejection fraction & 0,9681 & 0,9429 to 0,9939 & 0,0156 & 0,9657 & 0,9383 to 0,9938 & 0,0311 \\
\hline \multicolumn{7}{|l|}{$\begin{array}{l}A C E-I \text { or } A R B \geq 50 \% \text { of } \\
\text { target dose at } 3 \text { months }\end{array}$} \\
\hline Age & 0,9773 & 0,9595 to 0,9955 & 0,0146 & 0,9730 & 0,9517 to 0,9947 & 0,0152 \\
\hline Gender & 0,5474 & 0,3274 to 0,9154 & 0,0216 & & & \\
\hline Discharge creatininemia & 0,9945 & 0,9631 to 1,0270 & 0,1379 & 1,0263 & 0,9879 to 1,0662 & 0,1823 \\
\hline Hypertension & 1,0769 & 0,6628 to 1,7499 & 0,7648 & & & \\
\hline Diabetes & 1,2531 & 0,7124 to 2,2041 & 0,4336 & & & \\
\hline Ischemic heart disease & 1,1772 & 0,7223 to 1,9185 & 0,5126 & & & \\
\hline Treatment at discharge & 1,5222 & 0,9262 to 2,5016 & 0,0974 & 5,6730 & 3,0614 to 10,5127 & $<0,0001$ \\
\hline Discharge systolic blood pressure & 1,0038 & 0,9911 to 1,0167 & 0,5620 & & & \\
\hline Ejection fraction & 0,9728 & 0,9475 to 0,9988 & 0,0402 & & & \\
\hline $\begin{array}{l}\text { Betablockers } \geq 50 \% \text { of } \\
\text { target dose at discharge }\end{array}$ & OR & $\mathrm{Cl}$ & $\mathrm{p}$ & OR & $\mathrm{Cl}$ & $\mathrm{p}$ \\
\hline Age & 0,9970 & 0,9766 to 1,0180 & 0,7801 & & & \\
\hline Gender & 0,8476 & 0,4484 to 1,6020 & 0,6106 & & & \\
\hline COPD & 0,7232 & 0,3400 to 1,5382 & 0,0039 & 1,6848 & 0,7035 to 4,0347 & 0,2417 \\
\hline Diabetes & 1,5757 & 0,8264 to 3,0044 & 0,1673 & & & \\
\hline Ischemic heart disease & 1,2380 & 0,6859 to 2,2344 & 0,0478 & 1,5116 & 0,6717 to 3,4016 & 0,3181 \\
\hline Ejection fraction & 0,9991 & 0,9689 to 1,0303 & 0,9547 & & & \\
\hline Treatment on admission & 2,6149 & 1,3965 to 4,8962 & 0,0027 & 1,0023 & 0,9973 to 1,0073 & 0,3704 \\
\hline Discharge heart rate & 0,9726 & 0,9487 to 0,9972 & 0,0291 & & & \\
\hline Discharge systolic blood pressure & 1,0064 & 0,9913 to 1,0217 & 0,4107 & & & \\
\hline \multicolumn{7}{|l|}{$\begin{array}{l}\text { Betablockers } \geq 50 \% \text { of } \\
\text { target dose at } 3 \text { months }\end{array}$} \\
\hline Age & 0,9929 & 0,9759 to 1,0102 & 0,4178 & & & \\
\hline Gender & 0,7650 & 0,4551 to 1,2858 & 0,3120 & & & \\
\hline COPD & 0,3391 & 0,1756 to 0,6550 & 0,0013 & 0,3710 & 0,1840 to 0,7480 & 0,0018 \\
\hline Diabetes & 0,8845 & 0,5041 to 1,5520 & 0,6687 & & & \\
\hline Ischemic heart disease & 0,9287 & 0,5699 to 1,5132 & 0,7663 & & & \\
\hline Ejection fraction & 0,9736 & 0,9485 to 0,9993 & 0,4383 & & & \\
\hline Treatment on admission & 0,1586 & 0,0820 to 0,3065 & $<0,0001$ & 4,2203 & 2,2016 to 8,0898 & $<0.0001$ \\
\hline Discharge heart rate & 0,9968 & 0,9797 to 1,0141 & 0,7122 & & & \\
\hline Discharge systolic blood pressure & 1,0052 & 0,9926 to 1,0179 & 0,4228 & & & \\
\hline
\end{tabular}

Table 3: Relationships between prescription of HF treatments at discharge and clinical characteristics. Continuous variables were analysed by ANOVA and categorical variables by Chi2 test. Variables associated with $p \leq 0.20$ were tested in multivariate logistic regression. Admission or discharge treatment corresponds to analysed treatment in each row.

and early follow-up has been discussed very little. By comparing medications during an index consultation with discharge (about 6 months before index consultation), authors reported poor changes in the rates of main HF medications in patients with reduced LVEF [23]. By using a large national health insurance database, very few changes in the use of evidence-based HF medications between the period before hospitalization and 30 days later were reported [24]. Our results further refine these points. Our study shows that improvement in medical treatment is made during the hospitalization but not after discharge. We looked for characteristics that could explain the use of HF treatment as well as changes in treatment. As expected, previous use of evidence-based HF medications was by far the strongest predictor of their later usage either at discharge or 3 months after discharge that was also found in the get with the Guidelines-Heart Failure registry [25]. Besides and also unsurprisingly, age was related negatively to the use of HF medications, and COPD was linked to the lack of prescription of beta-blockers at discharge. With MRA, the usage rate in our survey is clearly insufficient, even if we take into account the guidelines applied at the time of inclusion, and the usual contra-indications -severe renal dysfunction and kaliemia $\geq 5.0 \mathrm{mM}$ - were observed in less than $20 \%$ and $10 \%$ respectively. An explanation for the lower usage of MRA in our cohort is that our survey is more representative of real life, with many hospitals participating. 
In many cases, the absence of initiating therapy or an increase of dosage is likely out of concern for possible intolerance. In ambulatory practice, practitioners may prefer to stop increasing the dose of a drug before intolerance occurs, because some adverse events (bradycardia and/or hypotension) are less easily manageable outside hospital. Secondly, the concept of the 'futility' of increasing the dose of a drug shows that the strategy of increasing the dosage to the maximum tolerated level, regardless of the patient's well-being, has not been fully integrated or accepted. Many strategies have been recommended in order to improve the management of HF patients after discharge. For example, an early post-discharge visit is strongly recommended in the current guidelines (5) and it has been reported that there is a strong relationship between the delay of this post-discharge consultation and the outcome [26]. In our study, the delay between discharge and the first outpatient visit was not recorded, but it must be pointed out that $12 \%$ of our patients had no consultation during the 3 months following discharge. Other transitional care service strategies, including followup phone calls, visiting nurses, telemonitoring, and home weight monitoring have shown some usefulness [27]. Therefore it should be possible to achieve target doses of key medications and improve symptoms without adversely affecting side effect symptoms, electrolytes or renal function.

The death rate in HF patients is much higher after discharge than in chronic HF patients without hospitalization [28]. By using the large OPTIMIZE-HF cohort, authors alearly remove clearly that the initiation of beta-blockers during hospitalization as well as its continuation at discharge was protective against the risk of subsequent events during the one-year post discharge, irrespective of others clinical variables $[29,30]$. In our study, we show that the use of ACE-I/ARB and betablockers rate $>50 \%$ of the target dose at 3 months remains protective against the risk of death for the next 9 months. Again, this demonstrates the need to treat all eligible patients.

\section{Limitations}

The first limitation was our inability to obtain the prescriptions for all patients during the 3 months after discharge. This follow-up was only accepted by $35 \%$ of the participating hospitals. There was no significant difference in clinical characteristics or discharge treatment compared to the whole cohort, and the relatively small number of patient and of death weakens our Cox analysis of the prognostic impact of treatment. Secondly, the OFICA was not designed to obtain medical justifications for the lack of prescription of HF-related drugs. Whilst the reasons justifying the prescription of HF-related drugs would appear to be useful data, the acquisition of comprehensive, reliable data is relatively modest for a large multi-centric survey. Therefore our results have to be interpreted cautiously. Thirdly, there was a relatively long interval between the OFICA survey and this analysis. Since the inclusion of patients in the OFICA survey, new guidelines have been published, including new drugs such as ivabradine or Angiotensin Receptors Neprylisin inhibitors, and it can be speculated that practitioners have been further educated and, for example, prescribe MRA more frequently.

\section{Acknowledgement}

We thank Geneviève Mulak and Frederique Fortin (French Society of Cardiology) and research officers of the clinical research unit Paris-Est for data management. We thank the College National des Cardiologues des Hôpitaux Généraux for invaluable help. We thank all investigators for their contribution to the study.

\section{References}

1. Jhund PS, Macintyre K, Simpson CR, Lewsey JD, Stewart S, et al. (2009) Long-term trends in first hospitalization for heart failure and subsequent survival between 1986 and 2003: A population study of 5.1 million people. Circulation 119: 515-523.

2. Bueno H, Ross JS, Wang Y, Chen J, Vidán MT, et al. (2010) Trends in length of stay and short-term outcomes among Medicare patients hospitalized for heart failure, 1993-2006. JAMA 303: 2141-2147.

3. Heidenreich PA, Albert NM, Allen LA, Bluemke DA, Butler J, et al. (2013) Forecasting the impact of heart failure in the United States: A policy statement from the American Heart Association. Circ Heart Fail 6: 606-619.

4. Ambrosy AP, Fonarow GC, Butler J, Chioncel O, Greene SJ, et al. (2014) The global health and economic burden of hospitalizations for heart failure: lessons learned from hospitalized heart failure registries. J Am Coll Cardiol 63: 11231133.

5. Ponikowski P, Voors AA, Anker SD, Bueno H, Cleland JGF, et al. (2016) Authors/Task Force Members, Document Reviewers. 2016 ESC Guidelines for the diagnosis and treatment of acute and chronic heart failure: The Task Force for the diagnosis and treatment of acute and chronic heart failure of the European Society of Cardiology (ESC) Developed with the special contribution of the Heart Failure Association (HFA) of the ESC. Eur Heart J 18: 891-975.

6. Yancy CW, Jessup M, Bozkurt B, Butler J, Casey DE, et al. (2016) 2016 ACC/ AHA/HFSA Focused Update on New Pharmacological Therapy for Heart Failure: An Update of the 2013 ACCF/AHA Guideline for the Management of Heart Failure: A Report of the American College of Cardiology/American Heart Association Task Force on Clinical Practice Guidelines and the Heart Failure Society of America. J Am Coll Cardiol 68: 1476-1488.

7. Lenzen MJ, Boersma E, Reimer WJMSO, Balk AHMM, Komajda M, et al. (2005) Under-utilization of evidence-based drug treatment in patients with heart failure is only partially explained by dissimilarity to patients enrolled in landmark trials: A report from the Euro Heart Survey on Heart Failure. Eur Heart J 26: 2706-2713.

8. Groote P, Isnard R, Assyag P, Clerson P, Ducardonnet A, et al. (2007) Is the gap between guidelines and clinical practice in heart failure treatment being filled? Insights from the IMPACT RECO survey. Eur J Heart Fail 9: 1205-1211.

9. Maggioni AP, Anker SD, Dahlström U, Filippatos G, Ponikowski P, et al. (2013) Are hospitalized or ambulatory patients with heart failure treated in accordance with European Society of Cardiology guidelines? Evidence from 12,440 patients of the ESC Heart Failure Long-Term Registry. Eur J Heart Fail 15: 1173-1184.

10. Komajda M, Anker SD, Cowie MR, Filippatos GS, Mengelle B, et al. (2016) Physicians' adherence to guideline-recommended medications in heart failure with reduced ejection fraction: data from the QUALIFY global survey. Eur J Heart Fail 18: 514-522.

11. Fonarow GC, Abraham WT, Albert NM, Stough WG, Gheorghiade M, et al (2009) OPTIMIZE-HF Investigators and Hospitals. Age- and gender-related differences in quality of care and outcomes of patients hospitalized with heart failure (from OPTIMIZE-HF). Am J Cardiol 104: 107-115.

12. Flaherty JD, Rossi JS, Fonarow GC, Nunez E, Stough WG, et al. (2009) Influence of coronary angiography on the utilization of therapies in patients with acute heart failure syndromes: findings from Organized Program to Initiate Lifesaving Treatment in Hospitalized Patients with Heart Failure (OPTIMIZEHF). Am Heart J 157: 1018-1025.

13. Kul S, Barbiere A, Milan E, Montag I, Vanhaecht K, et al. (2012) Effects of care pathways on the in-hospital treatment of heart failure: a systematic review. BMC Cardiovasc Disord 12: 81-89.

14. Gjesing A, Schou M, Torp-Pedersen C, Kober L, Gustafsson F, et al. (2013) Patient adherence to evidence-based pharmacotherapy in systolic heart failure and the transition of follow-up from specialized heart failure outpatient clinics to primary care. Eur J Heart Fail 15: 671-678.

15. Logeart D, Isnard R, Resche-Rigon M, Seronde MF, Groote P, et al. (2013) Current aspects of the spectrum of acute heart failure syndromes in a real-life setting: the OFICA study. Eur J Heart Fail 15: 465-476.

16. Asghar H, Rahko PS (2010) Quality of heart failure management: a comparison of care between a comprehensive heart failure program and a general cardiology practice. Congest Heart Fail 16: 65-70.

17. Zarrinkoub R, Kahan T, Johansson SE, Wändell P, Mejhert M, et al. (2016) How to best assess quality of drug treatment in patients with heart failure. Eur $\mathrm{J}$ Clin Pharmacol 72: 965-975. 
Citation: Berthelot E, Eicher JC, Salvat M, Seronde MF, de Groote P, et al. (2018) Medical Inertia in the Optimization of Heart Failure Treatment after Discharge and its Relationship to Outcome. Health Care Current Reviews 6: 221. doi: 10.4172/2375-4273.1000221

18. Groote P, Isnard R, Clerson P, Jondeau G, Galinier M, et al. (2009) Improvement in the management of chronic heart failure since the publication of the updated guidelines of the European Society of Cardiology. The ImpactReco Programme. Eur J Heart Fail 11: 85-91.

19. Greene SJ, Fonarow GC, Vaduganathan M, Khan SS, Butler J, et al. (2015) The vulnerable phase after hospitalization for heart failure. Nat Rev Cardiol 12: $220-229$.

20. Lebeau JP, Cadwallader JS, Aubin-Auger I, Mercier A, Pasquet T, et al. (2014) The concept and definition of therapeutic inertia in hypertension in primary care: A qualitative systematic review. BMC Fam Pract 15: 130

21. Zonszein J, Groop PH (2016) Strategies for Diabetes Management: Using Newer Oral Combination Therapies Early in the Disease. Diabetes Ther 7: 621639.

22. Redon J, Mourad JJ, Schmieder RE, Volpe M, Weiss TW (2016) Why in 2016 are patients with hypertension not $100 \%$ controlled? A call to action. J Hypertens 34: 1480-1488.

23. Solal AC, Leurs I, Assyag P, Beauvais F, Clerson P, et al. (2012) Optimization of heart FailUre medical Treatment after hospital discharge according to left ventricular ejection fraction: the Future survey. Arch Cardiovasc Dis 105: 355365.

24. Tuppin P, Cuerq A, de Peretti C, Fagot-Campagna A, Danchin N, et al. (2013) First hospitalization for heart failure in France in 2009: Patient characteristics and 30-day follow-up. Arch Cardiovasc Dis 106: 570-585
25. Krantz MJ, Ambardekar AV, Kaltenbach L, Hernandez AF, Heidenreich PA, et al. (2011) Patterns and predictors of evidence-based medication continuation among hospitalized heart failure patients (from Get With the Guidelines-Heart Failure). Am J Cardiol 107: 1818-1823.

26. Hernandez AF, Greiner MA, Fonarow GC, Hammill BG, Heidenreich PA, et al. (2010) Relationship between early physician follow-up and 30-day readmission among Medicare beneficiaries hospitalized for heart failure. JAMA 303: 17161722.

27. Van Spall HG, Rahman T, Mytton O, Ramasundarahettige C, Ibrahim Q, et al. (2017) Comparative effectiveness of transitional care services in patients discharged from the hospital with heart failure: A systematic review and network meta-analysis. Eur J Heart Fail 19: 1427-1443.

28. Maggioni AP, Dahlström U, Filippatos G, Chioncel O, Leiro MC, et al. (2010) EURObservational Research Programme: The Heart Failure Pilot Survey (ESC-HF Pilot). Eur J Heart Fail 12: 1076-1084.

29. Fonarow GC, Abraham WT, Albert NM, Stough WG, Gheorghiade M, et al. (2008) Influence of beta-blocker continuation or withdrawal on outcomes in patients hospitalized with heart failure: Findings from the OPTIMIZE-HF program. J Am Coll Cardiol 52: 190-199.

30. Hernandez AF, Hammill BG, O'Connor CM, Schulman KA, Curtis LH, et al. (2009) Clinical effectiveness of beta-blockers in heart failure: Findings from the OPTIMIZE-HF (Organized Program to Initiate Lifesaving Treatment in Hospitalized Patients with Heart Failure) Registry. J Am Coll Cardiol 53 184-192. 